\title{
EDUCAÇÃO NÃO-FORMAL SOBRE REPRODUÇÃO ASSISTIDA: DIVULGAÇÃO CIENTÍFICA NA FOLHA DE S.PAULO
}

\author{
NON-FORMAL EDUCATION ON ASSISTED REPRODUCTION: SCIENTIFIC DIVULGING IN THE \\ FOLHA DE S. PAULO NEWSPAPER
}

\author{
Clecí Körbes ${ }^{1}$ \\ Noela Invernizzi ${ }^{2}$
}

Resumo Neste artigo, analisamos as matérias publicadas pelo jornal Folha de S.Paulo, no ano de 2005, sobre reprodução assistida (fertilização in vitro e outras técnicas). A análise é feita sob dois ângulos. Primeiramente, examinamos que informação é divulgada ao público sobre reprodução assistida, tendo como foco os direitos reprodutivos, o acesso público e privado às tecnologias de reprodução assistida, os interesses envolvidos e os riscos dessas tecnologias. Constatamos que não houve divulgação das leis que garantem acesso gratuito à reprodução assistida no Brasil, apesar da aprovação, naquele ano, da Política Nacional de Direitos Sexuais e Reprodutivos. As reportagens enfatizam o caráter privado do acesso às tecnologias reprodutivas e confrontam interesses comerciais envolvidos. Destacam os avanços tecnológicos como benefícios universais, sem discutir como as desigualdades sociais afetam o acesso a essas tecnologias e tratamentos. Na escassa referência aos riscos relacionados com os procedimentos, destacam a gravidez múltipla, que afeta, paradoxalmente, os casais mais pobres. Em segundo lugar, indagamos que tipo de educação não-formal é desenvolvido através dos artigos do jornal sobre reprodução assistida. Os artigos examinados mostram, ao mesmo tempo, características de divulgação científica e do mais tradicional papel desenvolvido pela mídia como formadora de opinião.

Palavras-chave divulgação científica; formação de opinião; educação não-formal; reprodução assistida; direitos reprodutivos.
Abstract In this article, we analyze pieces published by the Folha de S.Paulo newspaper, in 2005, about assisted reproduction (in vitro fertilization and other techniques). The analysis is done from two angles. First, we examine what information is disclosed to the public about assisted reproduction, focusing on reproductive rights, on public and private access to assisted reproduction technologies, the interests involved, and the risks of these technologies. We found that there was no discussion regarding the laws that guarantee free access to assisted reproduction in Brazil, despite the approval, that year, of the National Policy on Sexual and Reproductive Rights. The reports emphasize the private nature of access to reproductive technologies and confront the commercial interests involved. They highlight the technological progress that has been made, such as universal benefits, but do not discuss how social inequalities affect access to these technologies and treatments. In the sparse reference to the risks associated with the procedures, they highlight multiple pregnancies which, paradoxically, affect poorer couples. Secondly, we questioned what kind of non-formal education is provided through the newspaper articles on assisted reproduction. The articles that were reviewed play both the role of disseminating the issue scientifically and the more traditional role the media play as opinion makers.

Keywords scientific dissemination; opinion making; non-formal education; assisted reproduction; reproductive rights. 


\section{Introdução}

O objetivo deste trabalho 3 é analisar as informações veiculadas sobre reprodução humana assistida no jornal Folha de S.Paulo durante o ano de 2005, mais especificamente no que se refere aos direitos reprodutivos, acesso às tecnologias de reprodução assistida, interesses envolvidos e riscos associados a essas tecnologias. O tema é particularmente desafiador, pois se trata de avanços científico-tecnológicos de ponta que estão próximos do cotidiano de muitas pessoas, resultando assim interessante não somente avaliar como se faz divulgação científica, mas também como se equaciona o binômio tecnologia-sociedade nessa empreitada. Para fazer a análise das reportagens, tomaremos como base que a divulgação científica na mídia não é um processo espontâneo, mas intencional, metódico, organizado e sistemático, caracterizando-se como forma de educação não-formal voltada à formação científica, política e sociocultural. Porém, apesar da pretensão de objetividade na transmissão de conhecimentos, a mídia também se ocupa da difusão de modos de compreender o mundo, de opiniões e perspectivas, compondo um espaço de educação informal.

Elegemos o ano de 2005 devido a dois marcos legais importantes aprovados no período: a Lei de Biossegurança n. ${ }^{\circ} 11.105 / 05$ (que autoriza pesquisas com células-tronco de embriões excedentes da fertilização in vitro e congelados há mais de três anos) e a Política Nacional de Direitos Sexuais e Direitos Reprodutivos, do Ministério da Saúde, aprovada em 22 de março de 2005 (que prevê, entre outras coisas, a oferta da reprodução assistida pelo Sistema Único de Saúde - SUS). Esta última teve como desdobramento a portaria n. ${ }^{\circ} 426 / G M$, de mesma data, que instituiu a Política Nacional de Atenção Integral em Reprodução Humana Assistida. Os marcos regulatórios aprovados estimularam nossa pesquisa, na expectativa de verificar como as polêmicas envolvidas na reprodução assistida são divulgadas à população pela mídia em questão.

De modo especial, chamou-nos a atenção o fato de que a assistência pública à concepção, preconizada na Nova Política de Direitos Sexuais e Reprodutivos, já era prevista nos artigos $3^{\circ}$ e $9^{\circ}$ da Lei de Planejamento Familiar n. ${ }^{\circ}$ 9.263/96, que regulamenta o artigo 226 da Constituição da República Federativa do Brasil de 1988, o qual garante o direito de formação de família. As leis e as tecnologias não são novas, ${ }^{4}$ mas nas últimas três décadas houve avanços significativos em técnicas científicas e aplicações médicas das tecnologias de reprodução assistida e a demanda por tratamentos é grande. ${ }^{5}$

Todavia, apesar de a infertilidade ser considerada um problema de saúde pública (Braz e Schramm, 2005), o acesso aos tratamentos é majoritariamente privado e de alto custo. Nos países em desenvolvimento, como o Brasil, onde os recursos públicos para a saúde são bastante escassos, onde há doen- 
ças graves (como a dengue e a malária) que ainda não são adequadamente tratadas e onde as metas nacionais incluem a redução da taxa de fecundidade, surge consequentemente a discussão sobre a justificativa de se investir em tratamentos de reprodução humana. Além disso, há o argumento de que seria mais apropriado aplicar os poucos recursos disponíveis em combater as causas de muitos casos de infertilidade: as infecções no aparelho reprodutivo, como a gonorreia e a clamídia, que nem sempre são diagnosticadas ou que são tratadas inadequadamente (Progress, 2003). No contexto dessas tensões, analisamos como o jornal aborda o acesso às tecnologias reprodutivas conceptivas.

A escolha do jornal Folha de S.Paulo se deu em virtude de ser o jornal de maior tiragem no país, com circulação nacional e por ter espaços dedicados à divulgação científica. Na apresentação eletrônica, o grupo Folha afirma que anuncia as mais importantes e mais recentes pesquisas e descobertas científicas do mundo, tratando os assuntos complexos com didatismo e utilização de recursos visuais, e que possui uma das mais capacitadas equipes de jornalistas.

Quanto à metodologia empregada, inicialmente escolhemos para teste $o$ mês de junho de 2005 e fizemos um levantamento do conteúdo sobre reprodução humana assistida e seus desdobramentos em cada uma das edições do jornal. Constatamos que as matérias relacionadas ao tema eram mais frequentes nas edições dos domingos, segundas e quartas-feiras. Por esta razão, optamos em limitar a busca às edições destes dias da semana para todos os meses do referido ano. A partir do levantamento inicial, estabelecemos um roteiro de análise com 15 aspectos. 6 Este artigo foca em quatro deles: direitos reprodutivos, acesso, interesses e riscos envolvidos, agrupados pela afinidade e complementaridade entre si.

\section{Infertilidade: a possibilidade das tecnologias reprodutivas}

No Brasil, ao tratarmos sobre a reprodução assistida, nos deparamos com a falta de consenso no emprego dos termos infertilidade e esterilidade. Algumas vezes são usados como sinônimos; em outras, com significações diferentes. Em face dessa confusão terminológica e considerando a ausência de diferenciações dos termos no dicionário brasileiro Larousse (Rodrigues, Nuno e Raggiotti, 2004), bem como que a incapacidade de conceber é denominada pela Organização Mundial da Saúde (OMS) de infertilidade (ou esterilidade) e infecundidade, utilizaremos neste texto os termos mais usuais, infertilidade e infecundidade, para denominar os casais que necessitam de ajuda médica e tecnológica para realizarem o desejo de terem filhos. ${ }^{7}$

No Brasil, é considerado infértil o casal que, mantendo relações sexuais frequentes sem uso de métodos contraceptivos, não concebe filhos em um 
ano a um ano e meio. Os dados estatísticos evidenciam que a infertilidade afeta cerca de $20 \%$ da população do país. As causas estão distribuídas, aproximadamente, como segue: $30 \%$ de causas masculinas, $30 \%$ femininas e $40 \%$ de fatores masculinos e femininos conjugados. 8

Nos tratamentos da infertilidade, as principais (e não únicas) tecnologias reprodutivas utilizadas são: a indução de ovulação associada com o coito programado, a Inseminação Intrauterina (IIU), também conhecida como Inseminação Artificial, a Fertilização in Vitro (FIV) e a Injeção Intracitoplasmática de Espermatozóide (ICSI).

Na Inseminação Intrauterina, após estimulação ovariana e monitoramento ultrassonográfico de ovulação, são injetados no útero espermatozóides originados de sêmen previamente preparado em laboratório. Ela pode ser homóloga (com sêmen do parceiro) ou heteróloga (com sêmen de doador).

Mais complexo, o processo de fertilização in vitro é constituído de quatro etapas principais: estimulação controlada dos ovários, punção ou coleta dos folículos que contêm os óvulos, fertilização laboratorial e transferência dos embriões obtidos para o útero. No Brasil, a lei permite a transferência de até quatro embriões; caso sejam obtidos mais que quatro, estes são congelados a temperaturas de $160^{\circ} \mathrm{C}$ negativos. Assim como a inseminação, a FIV pode ser homóloga ou heteróloga, mas tem o diferencial de possibilitar a utilização da conhecida barriga de aluguel, ${ }^{9}$ ou seja, a implantação do embrião ou embriões num útero saudável que não o da mãe biológica (ou da mãe que assume a maternidade, no caso de doação de células reprodutivas).

Convém salientar, também, que a fertilização laboratorial pode ocorrer de duas maneiras: juntando-se os gametas masculino e feminino em um meio de cultura e deixando que o espermatozóide penetre o óvulo naturalmente (FIV padrão) ou pela Injeção Intracitoplasmática de Espermatozóide (ICSI), na qual utilizam-se técnicas de micromanipulação, permitindo a seleção e injeção de um único espermatozóide dentro de cada óvulo.

Na seção seguinte, definiremos a educação não-formal e informal, a fim de dar suporte ao conceito de divulgação científica adotado na análise.

\section{Educação científica não-formal e informal na imprensa}

Na medida em que o desenvolvimento científico e tecnológico se acelera e tem impactos mais amplos na vida das pessoas, as escolhas realizadas no presente terão uma influência decisiva tanto nas trajetórias científicotecnológicas como na sociedade futura. Neste contexto, adquire importância significativa o acesso continuado a uma formação em ciências para o público leigo. Entendemos aqui por público leigo aquele não especializado 
em determinada ciência, o que inclui também os cientistas naqueles campos em que eles não se aprofundam.

Essa formação, que pode ocorrer em espaços de educação formal, nãoformal e informal, é indispensável para o público leigo se informar, refletir, conhecer e compreender os conteúdos, métodos e processos da ciência, se posicionar conscientemente sobre as aplicações e implicações da ciência e da tecnologia para a sociedade, participar da negociação de significados e até mesmo de decisões relacionadas ao desenvolvimento científico-tecnológico, além de ter acesso às tecnologias. Deste modo, a educação científica ao longo da vida torna-se uma condição de exercício da cidadania e de aprofundamento da democracia, adquirindo importância cada vez maior as diversas formas de divulgação científica. Cabe destacar que pesquisas internacionais indicam um forte interesse do público sobre ciência e tecnologia e, particularmente, sobre a ciência médica (Burns et al., 2003), na qual se enquadra nosso objeto de análise, a reprodução assistida.

A literatura educacional brasileira tradicionalmente fez referência a três tipos de educação: formal, não-formal e informal. Na literatura inglesa, de acordo com Cohen (2007), há autores que diferenciam educação não-formal e informal. No entanto, destaca que os dois termos são usados indistintamente e utiliza o termo 'educação informal' no sentido mais abrangente. A mesma situação (uso dos termos de educação não-formal e informal como sinônimos) é apontada no Brasil por Gohn (2006), mas a autora considera necessária a distinção entre os mesmos.

A educação formal é consensualmente conhecida como a educação escolar e caracteriza-se por ser sistemática, organizada, sequencial, realizada por profissionais habilitados em tempos e espaços definidos, regulamentada e avaliada por órgãos governamentais, geradora da expectativa de uma aprendizagem efetiva e motivada geralmente de modo mais extrínseco, podendo também haver motivação intrínseca. (Eshach, 2007; Gohn, 2006; Saviani, 2003). Nas palavras de Libâneo: “(...) a educação propriamente escolar se destaca dentre as demais formas de educação intencional por ser suporte e requisito delas" (Libâneo, 1994, p. 18).

As outras formas de educação são caracterizadas pelas diferenças com a educação formal. Todavia, essa distinção é um assunto repleto de controvérsias. De acordo com Marandino et al. (2004, p. 3) “em princípio, a distinção está fazendo referência àquele que educa, ao agente, à situação ou instituição, onde se situa o processo educativo". Esta classificação é somente uma tentativa de estabelecer diferenciações, que vêm acompanhadas de outras questões importantes, como por exemplo, a existência de duas espécies de educação com lógicas distintas. Nesta perspectiva, a primeira espécie inclui a educação formal e não-formal, que são dotadas de caráter metódico, organizado, sistemático e de intencionalidade do agente; a segunda abrange a 
educação informal, destituída das características da primeira espécie, embora haja questionamentos sobre este aspecto.

Desta forma, as duas espécies são constituídas por funções e processos educativos específicos. As formas de educação formal e não-formal possuem a intencionalidade explícita de transmitir conhecimentos, têm pretensão de objetividade (embora isso não signifique neutralidade), de apresentar versões contraditórias sobre um fato etc., e são reguladas e fiscalizadas por alguma autoridade, enquanto que no outro caso isso pode estar totalmente ausente. A educação informal costuma ser entendida no Brasil como modos de entender o mundo permeados por ideologias, 10 valores, opiniões e perspectivas.

A educação informal é definida como aquela que acontece espontaneamente no processo de socialização cotidiana, no espaço familiar, nos parques, nas ruas e até mesmo nas escolas, por exemplo, nos horários de lanche. Não é sistematicamente estruturada, mediada e nem avaliada por alguma entidade (Eshach, 2007; Gohn, 2006; Libâneo, 1994). Volta-se à aprendizagem de hábitos, atitudes, valores e sentimentos de pertencimento (Gohn, 2006).

A educação não-formal é compreendida como aquela desenvolvida nas experiências e ações coletivas intencionais que podem ser organizadas em virtude de circunstâncias históricas, como uma associação de bairro, um órgão colegiado na escola e um sindicato. A motivação é geralmente intrínseca (voluntária) e a aprendizagem resultante está vinculada, notadamente, ao exercício da cidadania (Gohn, 2006). Centros de ciência, museus de ciência e planetários são vistos como espaços de educação não-formal (Eshach, 2007).

O lugar da educação desenvolvida pelos meios de comunicação de massa não é consensual. Gohn (2006) os considera tanto agentes educadores informais como não-formais. Libâneo (1994) os classifica dentro da educação não-formal. Nossa perspectiva é que a mídia difunde conhecimentos de modo informal, na medida em que uma de suas funções primordiais é a formação de opinião e não é avaliada por órgão externo. Entretanto, a profissionalização crescente do jornalismo científico, junto com o peso significativo das questões científico-tecnológicas na vida cotidiana, tem levado a mídia a desenvolver espaços de educação não-formal voltados à divulgação científica, o que implica meios bem estruturados e avaliados que variam para responder ao grande leque de personalidades, estilos de aprendizagem, origens sociais e educacionais das pessoas que entram em contato com experiências de educação científica. Portanto, estabelecemos a diferenciação entre educação não-formal e informal mais como uma estratégia para chamar a atenção para o duplo caráter da mídia como meio de aprendizagem científica continuada e meio de formação de opinião.

Assim como não há consenso nas definições entre educação não-formal e informal, também não há acordo sobre uma série de aspectos relacionados à conceituação da divulgação científica ou popularização da ciência (Lozano, 
2005; Burns et al., 2003). Uma mesma atividade pode se enquadrar em diferentes modelos de divulgação da ciência, ou seja, uma atividade de divulgação não se encaixa em um modelo específico puro (Lewenstein, 2003; Lozano, 2005).

A exposição muito breve da analogia das vogais pode servir como parâmetro para pincelar os objetivos e funções da divulgação científica. Nesta analogia de Burns et al. (2003), autores australianos, a letra A, da palavra inglesa awareness, significa consciência, incluindo a familiarização com novos aspectos da ciência. A vogal E, de enjoyment, lembra a necessidade de se desfrutar, sentir prazer (ou outra resposta afetiva), como também apreciar a ciência como entretenimento ou arte. A vogal I, de interest, interesse, evidencia o voluntário envolvimento com a ciência ou sua comunicação. A vogal $\mathrm{O}$, de opinions, opiniões, lembra que a divulgação trata da formação, modificação ou confirmação das atitudes relatadas pela ciência. Por fim, U, de understanding of science, ou seja, compreensão da ciência remete à necessária compreensão dos conteúdos da ciência, seus processos e fatores sociais.

Lewenstein (2003) diferencia quatro tipos de divulgação da ciência: modelo de déficit, modelo contextual, modelo de perícia leiga e modelo de participação pública ou engajamento público. O primeiro levaria ao desenvolvimento de atividades para preencher a lacuna de conhecimento entre ciência e público. O segundo compreende que os indivíduos processam as informações com base em seus esquemas sociais e psicológicos moldados pelas experiências anteriores em seu contexto cultural e que, portanto, não são meros 'recipientes vazios'. Reconhece o poder das representações da mídia em aumentar ou diminuir o interesse público sobre determinadas questões. O terceiro modelo pressupõe que o conhecimento leigo pode ser tão relevante quanto o conhecimento técnico para a resolução de um problema; valoriza mais os conhecimentos locais do que os conhecimentos produzidos pela ciência moderna, razão pela qual chega a ser chamado de 'anticiência'. O quarto modelo surgiu focando uma série de atividades (como conferências de consenso, júris de cidadãos etc.) para aumentar a participação pública e elevar a confiança pública nas decisões de política da ciência. Destaca a importância da participação do público na discussão de questões técnico-científicas sem ceder o controle. Esse modelo, segundo Miller (2001), também é conhecido na Europa como modelo de diálogo entre ciência e público.

$\mathrm{Na}$ realidade brasileira ainda prevalece uma filosofia ou abordagem linear, que concebe a existência de um abismo entre ciência e público e enfatiza a transmissão ao invés do diálogo ciência-público. Não consideramos adequado o uso do termo alfabetização científica, de origem norte-americana, pois pressupõe que o público leigo é analfabeto científico. Preferimos utilizar a terminologia divulgação científica ou popularização da ciência, esta última mais utilizada na política do Ministério de Ciência e Tecnologia.11 
Tomamos como referência em nossa análise a diferenciação entre modelo de déficit e democrático adotada por Lozano (2005), segundo a qual a diferença essencial entre os modelos é a concepção do público e o tipo de divulgação promovida. O primeiro concebe que o público carece de conhecimentos científicos e o papel da popularização é suprir essas carências. O segundo reconhece o público como possuidor de conhecimentos, experiências, valores e interesses. Num modelo a linha de divulgação vai da ciência para o público e no outro há um processo de comunicação de dupla via entre ciência e público.

A seguir, analisamos a informação sobre reprodução assistida que chega ao público leigo pela Folha de S.Paulo e o tipo de formação ou educação promovida.

\section{Informação e formação sobre reprodução assistida na Folha de S.Paulo}

A informação sobre reprodução assistida nos textos da Folha de S.Paulo possui como característica principal a ênfase nos aspectos cognitivos: emprega linguagem científica ao explicar os procedimentos adotados pela ciência e utiliza os termos cunhados por ela, denotando uma aproximação entre a ciência e a mídia. A linguagem utilizada possibilita que a informação chegue com clareza ao público, isto é, sem apelo a termos eruditos ou a uma redação barroca. Cabe relembrar que os textos veiculados no jornal estão direcionados para um público com um nível consideravelmente alto de educação.

Também há utilização de uma linguagem objetiva, direta, concisa, com eliminação de influências subjetivas e opiniões preconcebidas, mas nas matérias há interferências mais ou menos sutis da subjetividade dos autores. Outra marca dos textos analisados é a linguagem didática, isto é, o uso de esquemas, ilustrações, resumos, seções de perguntas e respostas para facilitar a compreensão da informação pelo leitor, sem simplificação excessiva. Um mesmo texto pode combinar vários tipos de linguagens citados.

O conjunto de matérias analisadas ocupa predominantemente espaços do jornal voltados à divulgação da ciência, tais como a Folha Ciência, a coluna Ciência em Dia e a seção Mais Ciência. Treze artigos analisados integram tais seções. Outros nove apresentam informações sobre questões da vida cotidiana no Brasil e no mundo, situando-se nas seções Folha Cotidiano e Folha Mundo. Apenas um artigo é de opinião.

Na sequência, analisaremos como são abordadas, nas matérias selecionadas, quatro questões de fundamental importância na perspectiva da divulgação científica como dimensão de cidadania: as relacionadas ao debate sobre os direitos reprodutivos, as condições de acesso às tecnologias de reprodução assistida, os interesses envolvidos e os riscos associados às tecnologias reprodutivas. 


\section{Direitos reprodutivos}

Direitos reprodutivos é um tema escassamente tratado nas matérias revisadas. Apenas em quatro do total de 23 matérias publicadas se faz referência ao assunto (conforme Gráfico 1) e, de modo geral, cita-se a legislação de outros países, omitindo as leis mais significativas da área no Brasil. Por exemplo, Collucci (2005e, p. C4) afirma que na Bélgica "o sistema público de saúde custeia até seis ciclos de FIV para mulheres com menos de 43 anos", indicando que a Holanda e a Finlândia também custeiam tratamentos, mas não se refere à existência deste direito no Brasil. Chama a atenção a completa ausência de referências à Nova Política Nacional de Direitos Sexuais e Reprodutivos, do Ministério da Saúde, aprovada em março de 2005, a qual trata do acesso às tecnologias reprodutivas através do Sistema Único de Saúde (SUS).

Gráfico 1

Direitos reprodutivos na Folha de S.Paulo

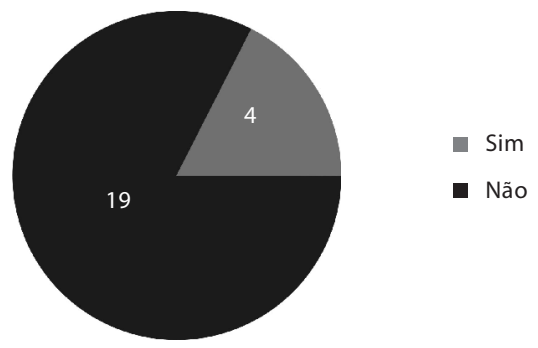

Fonte: As autoras, com base nas matérias selecionadas.

Como segundo exemplo, a matéria de Collucci (2005d, p. C5) menciona que na Europa alguns países custeiam o tratamento, mas há entraves por conta de questões éticas que acabam restringindo algumas técnicas, como a Alemanha que "(...) limita o atendimento gratuito a mulheres com até 37 anos, só permite a transferência de dois embriões para o útero e não realiza fertilização com óvulos doados".

Outras duas matérias fazem referência aos direitos dos pacientes submetidos a tratamentos. A mesma jornalista (Collucci, 2005a), referindo-se à oferta da técnica de fertilização in vitro com óvulos congelados, aborda o direito de informação e consentimento dos pacientes e cita o posicionamento do presidente da Sociedade Brasileira de Reprodução Assistida (SBRA), que "não vê problema em oferecer o serviço desde que o médico informe à paciente que a técnica é experimental e que não há garantia de gravidez". 
Na reportagem de Amato (2005), há indicação de que somente os genitores poderiam impedir o uso de embriões excedentes (congelados) de FIV em pesquisas com células-tronco embrionárias, as quais são anunciadas pelos cientistas como possuidoras de grande potencial terapêtico, por serem capazes de gerar qualquer tecido do organismo.

Considerando o conjunto de matérias analisadas, constatamos que o paciente é sempre apontado como beneficiário do desenvolvimento de novas técnicas, como a fertilização de óvulos congelados e as curas a partir de pesquisas com células-tronco embrionárias humanas (assunto que recebeu bastante atenção nas matérias). Entretanto, esse discurso genérico sobre benefícios universais do avanço científico-tecnológico para os pacientes contrasta com a escassa divulgação dos direitos reprodutivos, das políticas públicas e das leis que garantem acesso às tecnologias que, como veremos, têm alto custo.

\section{Serviços privados versus serviços públicos: acesso às tecnologias de reprodução assistida}

A infertilidade é um problema de saúde pública, que tende a se agravar devido a fatores comportamentais e ambientais. 12 No caso da infertilidade, a definição de saúde formulada pela OMS como completo bem-estar biopsicossocial não é satisfeita (Braz e Schramm, 2005) quando não são asseguradas às pessoas as condições para a realização de tratamentos. Em nossa pesquisa, constatamos que das 23 reportagens analisadas, apenas seis tratam do acesso da população à reprodução assistida (Gráfico 2).

Gráfico 2

Acesso às tecnologias reprodutivas na Folha de S.Paulo

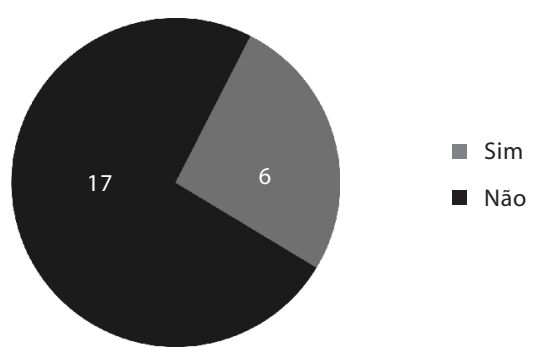

Fonte: As autoras, com base nas matérias selecionadas. 
Um dos aspectos discutidos é o acesso aos medicamentos utilizados em tratamentos. Collucci e Bassette (2005) citam que o citrato de clomifeno, que é um indutor de ovulação, custava em torno de vinte e oito reais. O preço relativamente acessível do medicamento tem gerado um problema recorrente comentado pela mídia: a venda de medicamentos sem receita médica. Uma das causas poderia ser a recusa das pacientes em ter terceiros (médicos) envolvidos no processo reprodutivo; outra poderia ser a dificuldade de acesso a uma consulta no SUS e os custos mais altos de acesso a consultas particulares.

Por outro lado, pacientes denunciam as vendas de medicamentos diretamente pelas clínicas e por distribuidoras que perguntam o nome do médico antes de informar o preço do medicamento. Na reportagem de Collucci (2005c), são exploradas versões de diversas fontes sobre a denúncia da existência de acordos entre médicos e distribuidoras: há suspeitas de que laboratórios oferecem dinheiro, presentes e patrocínios para viagens a médicos que indicarem seus produtos. De fato, um levantamento feito pela Folha de S.Paulo constatou que o preço dos medicamentos variava em $30 \%$, prática que fere o Código de Defesa do Consumidor, a legislação da Agência Nacional de Vigilância Sanitária (Anvisa) sobre comércio de medicamento, o Código de Ética Médica e a resolução do Conselho Federal de Medicina. Porém, laboratórios e distribuidoras negaram a prática.

Como os tratamentos costumam ser longos, os custos dos medicamentos são elevados. De acordo com Collucci (2005c), por ano são feitos no Brasil em torno de 12 mil ciclos de fertilização in vitro, em cerca de 100 clínicas reconhecidas e os gastos com medicamentos representam cerca de $50 \%$ do tratamento, que custava, naquele ano, a partir de seis mil reais por tentativa, sendo que os custos aumentam em clínicas mais sofisticadas.

Tendo em vista tais custos, o acesso às tecnologias de fertilização alça barreiras consideráveis para a média da população brasileira. Paradoxalmente, os custos são baixos e atrativos para os estrangeiros (Collucci, 2005d), colocando o Brasil na rota do turismo reprodutivo: “Nos EUA, cada tentativa de fertilização in vitro varia de US\$ 8 a $12 \mathrm{mil}$ - quase o dobro da média praticada no Brasil".

Uma maior permissividade das técnicas em relação a outros países seria mais um dos motivos para o aumento da procura, que no primeiro semestre de 2005 já era o dobro em relação a 2004. No Brasil há, pois, uma fragilidade na fiscalização das clínicas de reprodução assistida (Collucci, 2005e), possivelmente vinculada aos interesses das clínicas e laboratórios.

No nosso sistema de saúde pública há raros serviços que dispõem de tratamentos gratuitos ou semigratuitos. Luna (2007) pesquisou vários serviços públicos de reprodução humana e concluiu que todos impunham limitações de acesso (como idade da mulher e seu estado conjugal) e se discutia a adoção 
de critérios ainda mais restritivos (como renda familiar e filhos de casamentos anteriores) com a justificativa de que não há disponibilidade de recursos para atender a todos. Também constatou que há poucos centros capacitados para o atendimento convencional de esterilidade, e praticamente nenhum oferece a reprodução assistida de alta complexidade (FIV e ICSI). Além disso, a falta de recursos impossibilita a repetição de ciclos seguidos de fertilização, o que é geralmente a norma. Do total das seis matérias que abordam a questão do acesso, somente a de Collucci (2005e) se refere à oferta de FIV no serviço público, porém sem citar a existência do direito constitucional.

Quando a opção é pelo adiamento da maternidade, a medicina também mostra seus esforços e dúvidas, como na discussão do índice de eficácia da técnica de congelamento de óvulos, tendo em vista a reprodução assistida em idade tardia (Collucci, 2005a). A reportagem anuncia que a técnica custa aproximadamente cinco mil reais. Uma clínica diz oferecer gratuitamente a técnica em fase experimental.

Concluindo, a informação sobre o acesso às tecnologias de reprodução assistida oferecida pela Folha de S.Paulo é parca. As matérias focalizam no acesso privado a essas tecnologias, salientam os altos custos dos tratamentos, fazem alguma referência à dificuldade de acesso por famílias de renda mais baixa e não mencionam a legislação que afirma o direito de acesso gratuito. Assim, ao tratar numa minoria das matérias a questão do acesso, tende a predominar o discurso do avanço das tecnologias para o benefício de potenciais pacientes e o foco nas classes médias e altas, que são, de fato, as que têm acesso aos tratamentos, dada a escassez da oferta pública.

\section{Interesses envolvidos}

Quatro das matérias analisadas tratam o assunto dos interesses envolvidos com a reprodução assistida. A preocupação médica apresentada na reportagem de Collucci e Bassette (2005) de que muitas mulheres utilizam o medicamento de indução de ovulação sem monitoramento do ciclo ovulatório manifesta, numa análise rigorosa, a existência de interesses comerciais: a medicação pode ser obtida facilmente sem receita médica, o que indica o descaso com a legislação por parte daqueles que ofertam esses produtos, provavelmente devido à possibilidade de ampliação das vendas.

Em Lopes (2005b), uma paciente afirma em depoimento que tomou indutores de ovulação e depois se submeteu a três tentativas de Inseminação Artificial, "procedimento supercaro", sem sucesso. Porém, obteve a gravidez tomando insulina após orientação de especialista. Cabe questionar se os especialistas que a submeteram a três tentativas caras de Inseminação Intrauterina desconheciam a possibilidade de a paciente ter resistência à 
insulina, sendo que a administração do medicamento poderia ter aumentado as chances de sucesso nas tentativas pagas, ou se esta prática poderia ser a manifestação dos interesses comerciais das clínicas.

A matéria de Collucci (2005c) comenta as denúncias de pacientes sobre a existência de práticas de recebimento de comissões pelos médicos. Dirceu Pereira, secretário-executivo da Sociedade Brasileira de Reprodução Humana, confirmou que há 'boatos' sobre irregularidades e disse que isso é do fórum íntimo de cada médico. O termo 'boatos' dá a ideia de que as denúncias não têm origem conhecida que as torne autênticas (conforme Dicionário Larousse). Segundo a reportagem de Collucci (2005c), em levantamento feito pela Folha, constatou-se até $30 \%$ de variação no preço dos medicamentos. Poderiam os 'boatos' fornecer indícios da necessidade de uma investigação mais rigorosa?

Embora as tecnologias de reprodução assistida possam ser encontradas no serviço público brasileiro, de acordo com Costa (2006), elas foram introduzidas no Brasil por indústrias farmacêuticas e clínicas privadas, onde até hoje permanece instalada a maioria dos serviços.

Possíveis interesses comerciais podem estar implícitos no debate sobre a técnica de congelamento de óvulos (indicada em casos de câncer ou adiamento da maternidade): o médico de clínica particular se demonstra mais otimista que o de hospital universitário em relação ao sucesso da técnica. Para Roger Abdelmassih, dono de uma clínica privada, uma moderna técnica de congelamento rápido com redução de $37^{\circ} \mathrm{C}$ para $-196^{\circ} \mathrm{C}$ permite recuperar de $80 \%$ a $90 \%$ dos óvulos, dos quais $70 \%$ a $75 \%$ resultam em embriões, mas não arrisca o índice de gravidez. No entanto, afirma a obtenção de duas gestações após o descongelamento de óvulos, sem informar qual foi o número das tentativas que não resultaram em gravidez. Para o público leigo, o anúncio dessa alta taxa de formação de embriões pode ser compreendido como promessa de gravidez. 13

Já Artur Dzik, do Hospital Universitário Pérola Byington, não se refere às taxas que podem ser consideradas promissoras, mas enfatiza que, segundo dados científicos, seriam necessários 100 óvulos congelados para se obter uma gravidez, ou seja, o índice de sucesso de fertilização in vitro com óvulos congelados é de $1 \%$ (Collucci, 2005a). Segundo a reportagem, outro ginecologista, Arnaldo Schizzi Cambiaghi, da Universidade Federal de Minas Gerais (UFMG), afirmou que em duas oportunidades de fertilização os óvulos sobreviveram, mas não houve formação de embriões, justificando que isto teria acontecido pela má qualidade do sêmen, sem se referir à possibilidade de problemas nos óvulos descongelados.

O caso do congelamento de óvulos pode indicar a existência de interesse das jovens em novas técnicas para a gravidez tardia; e também o interesse dos médicos em se aprimorar nas novas técnicas, que representa desenvolvimento científico, desenvolvimento profissional e vantagem competitiva. 
É importante acrescentar que a doação de óvulos (processo em que mulheres com maior poder aquisitivo pagam a medicação para outras mais pobres que, em troca, doam seus óvulos) se apresenta como uma 'nova roupagem' da manutenção das desigualdades sociais (Castro, 2004).

Assim, consideramos que o jornal pesquisado oferece aos leitores elementos para a formação de uma opinião crítica em relação aos interesses envolvidos na difusão dos avanços relacionados à reprodução humana, apesar de que, como dissemos antes, as matérias tendam a apresentar tais avanços como benefícios universais.

\section{O risco da gravidez múltipla}

No conjunto de 23 matérias analisadas, dez abordaram a questão dos riscos, podendo uma matéria tratar de mais de um risco. Destas, seis se referiram aos riscos para a saúde humana e, entre estas, a gravidez múltipla foi o mais citado, razão pela qual o tomamos como central nesta análise. Outros riscos destacados foram a insegurança sobre a eficácia das técnicas (principalmente em relação à gravidez a partir de óvulos congelados e às terapias com células-tronco embrionárias, subprodutos da reprodução assistida) e o risco de uma nova eugenia, pelo viés da biologia (Gráfico 3). 14

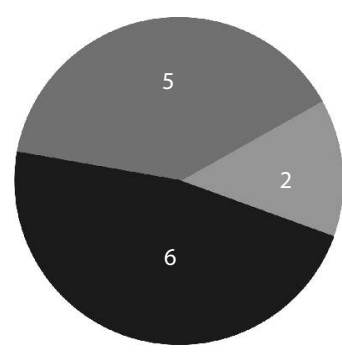

- Riscos para a saúde humana

- Insegurança sobre eficácia das técnicas

nova forma de eugenia

Fonte: As autoras, com base nas matérias selecionadas.

Muitas pessoas inférteis preferem correr riscos ao se submeterem aos tratamentos de reprodução assistida do que deixar de realizar a maternidade ou paternidade (biológica). De modo geral, as mulheres e os homens não estão preparados para a infertilidade, acreditando serem férteis. Uma das explicações para esse fenômeno é que a educação sexual recebida ao longo 
da vida costuma focar na noção de fertilidade, assim como o processo mais geral de reprodução cultural dos valores ligados à paternidade e à maternidade. Participam desse processo educativo, por exemplo, a família, a escola, a mídia, as instituições religiosas, os cientistas e os profissionais da saúde.

A título de elucidação, na infância, as crianças imitam o papel de mãe e/ou pai nas suas brincadeiras. Na adolescência, meninos e meninas recebem educação sexual na escola e/ou na família para usar preservativos, a fim de evitar doenças sexualmente transmissíveis e filhos indesejados, associando isso à ideia de que todos são férteis.

A mídia, por sua vez, a impressa e a televisiva, reforça uma identidade para as mulheres ligada ao corpo, à natureza, à reprodução e à maternidade, minimizando a noção da construção social e cultural de gênero. Por exemplo, a noção do feminino ligado à maternidade como papel adequado à mulher. Com isso, deixa de discutir as mudanças sociais que a família e maternidade vêm sofrendo nos últimos anos, possibilitadas entre outros fatores, pelas tecnologias reprodutivas (Körbes e Invernizzi, 2008b; Ribeiro e Rohden, 2009).

O próprio discurso científico, conforme explica Rohden (2008), como o discurso sobre ovários e hormônios no contexto do surgimento da endocrinologia (décadas de 20 a 30 do século XX), reforça o comportamento esperado das mulheres. Ao mesmo tempo, materializa as diferenças entre homens e mulheres e a oposição entre natureza e cultura, que vem sendo revista na perspectiva crítica da ciência que parte das teorias de gênero. Em trabalho anterior, a autora enfatiza que as fronteiras entre os sexos e entre o que era considerado natural e social já eram instáveis no século XIX, quando já se argumentava que as mulheres poderiam desenvolver outros papéis além da maternidade. No entanto, os textos médicos do período analisado pela autora procuravam provar que o corpo feminino era destinado à procriação, 0 que incapacitaria as mulheres para outras tarefas (Rohden, 2003).

Desse conjunto de processos formativos e de reprodução cultural resultam aprendizados que podem influenciar a tomada de decisões diante de um diagnóstico de infertilidade. Assim, só quando uma pessoa se depara com a infertilidade percebe o quanto sua educação foi unidirecional. A análise dos processos educativos sobre as características que idealmente distinguiriam homens e mulheres na natureza e na sociedade fornece dicas preciosas de que a construção de gênero se efetiva na interação do corpo biológico com o sujeito histórico-social.

Como dito anteriormente, um dos principais riscos associados à reprodução assistida é a gravidez múltipla. O nascimento de bebês múltiplos se tornou frequente no Brasil e já é considerado um problema de saúde devido aos riscos causados às mães e às crianças e ao alto custo para o sistema público de saúde, mas ainda não tem recebido a atenção necessária. As adversidades para a família tendem a ser muitas, incluindo aspectos econômicos e até emocionais, assim como podem ser as complicações para a saúde dos bebês (Tamanini, 2006). 
A gravidez múltipla e suas complicações são retratadas com muitos dados na matéria de Collucci (2005e, p. C4): “há mais chances de a gestante ter pré-eclâmpsia, tromboembolismo e diabetes gestacional. O bebê pode nascer com baixo peso, má-formação congênita e complicações cerebrais". Há maior risco de parto prematuro, de sequelas no bebê em razão da prematuridade, de possíveis infecções, e "além dos riscos à saúde da gestante e à do bebê, pesquisas mostram que o estresse da gestação e do nascimento de múltiplos aumenta as chances de divórcio". Afinal, o aumento de uma família de duas para cinco ou seis pessoas em pouco tempo exige grande preparação física, emocional e financeira do casal, fatores já prejudicados na luta por um filho (em geral longa). De acordo com especialistas, a gestação de dois bebês ou mais tende a se tornar mais um indicador de desenvolvimento humano.

A este respeito, de acordo com especialistas entrevistados pela Folha, o fator financeiro é um grande empecilho no Brasil para tornar viável a transferência de um único embrião, seja na rede pública ou privada e, por consequência, os riscos são maiores para a população de menor renda. Alguns casais aceitam as orientações médicas de transferir um número reduzido de embriões, mas quando a primeira FIV não dá certo se desesperam, querem a transferência de maior número de embriões e chegam a ignorar os riscos de uma gravidez múltipla (a reportagem cita alguns exemplos).

Segundo Collucci (2005e), a gravidez múltipla foi um dos assuntos mais debatidos no Congresso da Sociedade Europeia de Embriologia e Reprodução Humana, ocorrido em Copenhague. Países da Europa financiam o tratamento e orientam que seja transferido somente um embrião de ótima qualidade, sendo que em torno de $70 \%$ dos ciclos de FIV resultam na transferência de um único embrião. Já o Brasil "é um dos campeões do mundo em gravidez múltipla: $42 \%$ das gestações por FIV resultam em gêmeos, trigêmeos, quadrigêmeos e quíntuplos" (Collucci, 2005e, p. C4).

Entretanto, mesmo nos países desenvolvidos, os especialistas reconhecem fatores que levam os casais a transferir mais de um embrião, como a idade avançada da mulher, tentativas frustradas de gravidez (seu impacto físico e emocional), além da crença de que com mais embriões as chances de gravidez aumentam.

A reportagem da Folha de S.Paulo (2005a) exemplifica riscos que estão envolvidos numa gravidez múltipla em mulher de idade tardia. A inseminação artificial na romena de 66 anos resultou em uma gravidez de gêmeos, com a perda de uma das crianças seis semanas antes do prazo, pesando 700 gramas, e o nascimento da outra em parto de emergência, com 1,45 quilogramas, menos da metade do peso médio de um recém-nascido, sendo internada na Unidade de Terapia Intensiva (UTI). ${ }^{15}$ 
Outro risco associado aos tratamentos provém do uso de estimuladores de ovulação sem monitoramento médico, que pode provocar crescimento exagerado dos ovários, gravidez múltipla, aumento das chances de câncer de ovário, infertilidade por resistência à droga ou piora da qualidade do muco cervical e do endométrio (Collucci e Bassette, 2005). Boa parte das mulheres que faz uso de indutores de ovulação possui a Síndrome de Ovários Policísticos (SOP); Lopes (2005b) comenta os perigos associados a este problema de saúde, tais como aborto espontâneo, desenvolvimento de diabetes e infertilidade.

Na reportagem "Esterilidade preocupa mulher jovem" (Folha de S.Paulo, 2005c), é abordada a controvérsia da medicina entre seus limites e suas possibilidades de preservar a fertilidade em casos de câncer de mama em mulheres jovens. Nos estágios mais avançados da doença a mulher precisa se submeter à quimioterapia e/ou radioterapia, levando à infertilidade em cerca de metade dos casos.

Em face do posicionamento de muitas mulheres em não abdicar da maternidade, especialistas sugerem o congelamento de óvulos ou tecido ovariano para realizar a FIV mais tarde. Entretanto, dado que ainda não há tecnologia que garanta bons índices de gravidez com óvulos congelados e que há $50 \%$ de chances de a mulher entrar em menopausa após o tratamento do câncer, parte das mulheres se submete a FIV e congela os embriões, seja com sêmen do companheiro ou de doador, no caso das que não têm parceiro fixo. $\mathrm{O}$ médico Antonio Frasson, entrevistado pela Folha, alerta para o risco de que o hormônio estrógeno utilizado nas estimulações ovarianas possa contribuir, no caso da mulher ter receptor de estrógeno, para o crescimento de tumor, e sugere que o tratamento seja discutido minuciosamente.

À exceção deste último exemplo e da romena que foi mãe aos 66 anos, a Folha mostra, paradoxalmente, que as famílias com menores rendas estão mais sujeitas aos riscos da utilização de mecanismos reprodutivos, sobretudo ao risco da gravidez múltipla. De maneira geral, os artigos do jornal informam os leitores sobre os riscos associados a estas tecnologias, contemplando, assim, um interesse dos pacientes: o acesso à informação.

Com o fato de a gestação múltipla estar prestes a se tornar um indicador de desenvolvimento humano, volta-se à velha discussão sobre o que é prioridade em termos de investimento dos escassos recursos públicos destinados à saúde e fica-se numa dinâmica circular onde as causalidades estão interrelacionadas: a prevenção das causas da infertilidade poderia evitar gastos com tratamentos de reprodução humana; gastos com tratamentos de infertilidade diminuiriam os índices de gravidez múltipla e problemas a ela relacionados. A questão é que focando nesse círculo perde-se de vista que o problema não é a falta de recursos, mas sim são as desigualdades sociais. 


\section{Considerações finais}

As relações entre ciência, tecnologia e sociedade estão permeadas pelas relações de desigualdade social e envoltas por controvérsias. Essas relações sociais no seio das quais se desenvolvem a ciência e a tecnologia permanecem ocultas sob os problemas apontados nas notícias sobre riscos, acesso e implicações sociais das novas tecnologias.

No caso estudado, percebemos que a educação não-formal realizada pelo jornal envolve a formação de opinião do leitor. O progresso científico-tecnológico é apresentado como sinônimo de benefícios universais.

Entretanto, as matérias trabalham certas contradições na medida em que, além de informações sobre os potenciais benefícios das tecnologias reprodutivas, fornecem ao leitor informações sobre os riscos envolvidos nos procedimentos, revelam barreiras econômicas para o acesso às tecnologias e a existência de interesses comerciais que tornam esses tratamentos menos acessíveis.

Não obstante, o acesso às tecnologias reprodutivas através do SUS, garantido por lei, é escassamente abordado, tanto nos aspectos da legislação como da oferta real realizada pelos hospitais públicos. O foco, assim, se concentra no público de classe média e alta, leitores mais comuns da Folha de S.Paulo, enfatizando o acesso privado aos benefícios tratados comumente como universais.

As tecnologias de reprodução humana já estão consolidadas e trazem benefícios (e riscos) para as pessoas que conseguem acessá-las. Para as pessoas que não conseguem ou as acessam com muitas dificuldades, os riscos são maiores. Para essas, a esperança reside na ampliação da visão do círculo vicioso que limita a compreensão da questão. A mídia pode contribuir para essa transição da visão circular (onde sempre se volta ao mesmo ponto) para a espiral (onde nunca se retorna ao mesmo ponto).

A divulgação científica promovida pelo jornal estudado possibilita, por um lado, desenvolver a visão associada à imagem de uma espiral. Por exemplo, quando mostra que a falta de acesso aos tratamentos influencia os índices de gravidez múltipla. Por outro lado, permanece na circularidade ao tratar a inserção das tecnologias na sociedade como se fosse uma consequência inexorável do avanço tecnológico, ou seja, como se ao avanço tecnológico correspondesse igualdade de benefícios para todos. Esse tipo de abordagem parece estar relacionado a uma tensão entre os modelos de divulgação de déficit e o dialógico, que vem junto com a tensão entre o esforço de profissionalização dos jornalistas da divulgação científica realizada pelo jornal e o papel de cunho ideológico, de conformar visões de mundo, tradicionalmente exercido pela imprensa.

Nesse sentido, questionamos: quais seriam as possíveis razões para a não democratização das informações sobre os direitos reprodutivos? Possivel- 
mente pesem os interesses econômicos de clínicas e laboratórios e o fato de que a política reprodutiva, num país com tantas desigualdades, sempre apontou à limitação do número de filhos das camadas mais pobres da população e não em salvaguardar seus direitos reprodutivos, nem as condições de vida desses filhos. Contraditoriamente, como vimos, o principal risco envolvido na aplicação das tecnologias reprodutivas, a gravidez múltipla, afeta exatamente a população menos favorecida economicamente.

\section{Notas}

1 Bolsista pela Coordenação de Aperfeiçoamento de Pessoal de Nível Superior (Capes). Doutoranda em Tecnologia, área de concentração Tecnologia e Sociedade, pela Universidade Tecnológica Federal do Paraná (UTFPR), Curitiba, Paraná, Brasil. <cleci.korbes@gmail.com> Correspondência: Av. Sete de Setembro, 3.165, Bloco D, $3^{\circ}$ andar, Rebouças, CEP 80.230-901, Curitiba, Paraná, Brasil.

2 Professora adjunta do Setor de Educação da Universidade Federal do Paraná (UFPR) e professora colaboradora da Universidade Tecnológica Federal do Paraná (UTFPR), Curitiba, Paraná, Brasil. Doutora em Política Científica e Tecnológica pela Universidade Estadual de Campinas (Unicamp). <noela.invernizzi@gmail.com>

3 Este artigo se baseia na dissertação de mestrado Educação não-formal e informal em ciência e tecnologia: divulgação científica e formação de opinião sobre reprodução assistida e seus desdobramentos na Folha de S.Paulo, de autoria de Clecí Körbes, apresentada no Programa de Pós-Graduação em Educação, UFPR, Curitiba, 2008.

4 A primeira bebê de proveta de que se tem conhecimento é a britânica Louise Brown, nascida em 1978.

5 O programa Globo Repórter, que foi ao ar em 8 de julho de 2005 (pela Rede Globo de Televisão), afirmou que no Brasil o único hospital que oferece tratamentos de reprodução humana com gratuidade total era o Hospital Pérola Byington e que este estava com mais de 1,7 mil pacientes na fila de espera. Com base em dados do Censo de 2000 divulgados pela Folha de S.Paulo em 3 de fevereiro de 2005, especialistas estimam que no Brasil cerca de 500 mil casais necessitem de procedimentos mais complexos de reprodução humana, como a fertilização in vitro.

6 Os itens que constituíram o roteiro de análise na dissertação foram: linguagem; objetividade/posicionamento; fontes principais; lugar do artigo no jornal; como o artigo se refere ao público-alvo; quem é esse público-alvo; regulamentação da pesquisa e aplicação; bioética; interesses envolvidos; questões éticas e valores; direitos reprodutivos; relações de gênero; acesso; riscos; controvérsias; e outras observações.

7 No âmbito internacional, em especial nos países desenvolvidos, de acordo com Rutstein e Shah (2004), os termos infertilidade, esterilidade e infecundidade são frequentemente 
usados sem considerar uma definição precisa. Além disso, definições desses termos costumam diferir substancialmente entre usos demográficos e médicos, e entre línguas. Na terminologia demográfica do inglês, infertilidade ou esterilidade primária é definida como a incapacidade de ter filhos, devido à dificuldade para conceber ou levar a gravidez até o nascimento. Nos estudos médicos, entretanto, infertilidade é usualmente definida apenas como a incapacidade em conceber. Já o termo infecundidade, na linguagem demográfica inglesa, refere-se à incapacidade de conceber após vários anos de exposição à possibilidade de gravidez. Incapacidade de conceber em dois anos de exposição à gravidez é a definição epidemiológica recomendada pela Organização Mundial da Saúde (OMS). Porém, estudos clínicos frequentemente se referem ao período de um ano de tentativas e nos estudos demográficos é comum considerar um período de cinco anos.

8 Por outro lado, segundo dados da OMS, a taxa de fecundidade do Brasil no ano de 2006 era de 2,3 filhos por casal. As estatísticas do IBGE indicam que nos anos 1970 a taxa de fecundidade do brasileiro era três vezes maior; atualmente se aproxima de 2,1 e tende a cair para 1,8 até 2050. Mesmo assim, a política de planejamento familiar continua voltada à contracepção, porque os nascimentos são concentrados nas famílias de baixa renda.

9 Segundo matéria de Lopes (2008), no Brasil, as Normas dos Conselhos Regionais de Medicina permitem apenas o aluguel não remunerado de barriga entre parentes, exceto os estados de São Paulo e Minas Gerais que estendem a permissão para não parentes, desde que sem remuneração. De acordo com a reportagem, apesar de proibido, o aluguel remunerado de barriga tornou-se um negócio no Brasil.

10 Paulo Freire (1996) define a ideologia como o uso da linguagem para penumbrar a realidade.

11 Lozano (2005) lembra que os termos divulgação, popularização e vulgarização da ciência não são muito apropriados para se referir ao modelo de déficit complexo (e ao democrático), sendo propostos termos como compreensão pública e apropriação social da ciência e da tecnologia. Sugere que os termos utilizados na América Latina passem por uma reavaliação.

12 Alguns fatores comportamentais podem comprometer a fertilidade, tais como o tabagismo, a prática sexual sem o uso de preservativos (possibilidade de contrair doenças sexualmente transmissíveis), o abuso de álcool e drogas, alguns medicamentos usados no tratamento de gastrites, úlceras, hipertensão arterial e infecções urinárias, a obesidade e o sobrepeso, dietas e a prática de exercícios exagerados, o uso de anabolizantes, a decisão de adiar o nascimento do primeiro filho e o estresse.

13 Roger Abdelmassih, médico especialista em reprodução humana, teve sua credibilidade abalada em 2009, em razão de acusações de crimes sexuais contra pacientes. O médico permaneceu preso de agosto a dezembro de 2009 e se encontra impedido de exercer a profissão, conforme foi noticiado por vários jornais.

14 Para mais informações sobre os dois últimos riscos mencionados, ver Körbes (2008).

15 Iliescu não é, porém, a mãe mais velha do mundo. Em 2006, passou para o Livro Guinness de Recordes a espanhola María Del Carmen Bousada de Lara, que teve gêmeos aos 67 anos após se submeter a uma Inseminação Artificial nos Estados Unidos. Foi diagnosticada com câncer poucos meses após o nascimento dos bebês e faleceu em 2009. 


\section{Referências}

AMATO, Fábio. Procurador pede liminar para liberar pesquisas com embrião. Folha de S.Paulo, São Paulo, 02 fev. 2005. Folha Ciência, p. A 12.

BASSETTE, Fernanda. Cistos no ovário aumentam riscos de aborto espontâneo. Folha de S.Paulo, São Paulo, 30 out. 2005. Folha Cotidiano, p. C 6.

BRASIL. Lei $\mathrm{n}^{\circ}$ 9.263, de 12 de janeiro de 1996. Regula o parágrafo $7^{\circ}$ do artigo 226 da Constituição Federal, que trata do planejamento familiar. Diário Oficial da República Federativa do Brasil, Poder Executivo, Brasília, DF, 15 jan. 1996. Seção I, s.p. Partes vetadas: Diário Oficial da República Federativa do Brasil, Poder Executivo, Brasília, DF, 20 ago. 1997. Seção I, p. 17.989.

Portaria n. ${ }^{\circ}$ 426/GM, de 22 de março de 2005. Institui, no âmbito do SUS, a Política Nacional de Atenção Integral em Reprodução Humana Assistida. Diário Oficial da República Federativa do Brasil, Poder Executivo, Brasília, DF, 23 mar. 2005. Seção I, s.p.

Lei $\mathrm{n}^{\circ} 11.105$, de 24 de março de 2005. Estabelece normas de segurança e mecanismos de fiscalização de atividades que envolvam organismos geneticamente modificados - OGM e seus derivados, cria o Conselho Nacional de Biossegurança-CNBS, reestrutura a Comissão Técnica Nacional de Biossegurança - CTNBio, dispõe sobre a Política Nacional de Biossegurança - PNB e dá outras providências. Diário Oficial da República Federativa do Brasil, Poder Executivo, Brasília, DF, 28 mar. 2005.

BRAZ, Marlene; SCHRAMM, Fermin Roland. O ninho vazio: a desigualdade no acesso à procriação no Brasil e a bioética. Revista Brasileira de Bioética, v. 1, n. 2, 2005, p. 180-194. Disponível em: <www.sbbioetica.org.br/rbb/ RBBV-1-2.pdf>. Acesso em: 17 jun. 2007.
BURNS, Terri; O'CONNOR, John; STOCKLMAYER, Susan. Science communication: a contemporary definition. Public Understanding of Science, v. 12, n. 2, 2003, p. 183-202. SAGE Publications. Disponível em: <www. sagepublications.com>. Acesso em: 30 abr. 2007.

CASTRO, Cláudia Medeiros. Novas tecnologias reprodutivas, velhas desigualdades? Resenha. Revista Estudos Feministas, Florianópolis, v. 12, n. 2, maio/ago., p. 241-243, 2004.

COHEN, Erik H. Researching informal education: a preliminary mapping. Bulletin de méthodologie sociologique, Paris, n. 93, p. 7088, jan. 2007.

COLLUCCI, Cláudia. Jovens congelam óvulo para gravidez tardia. Folha de S.Paulo, São Paulo, 20 mar. 2005a. Folha Cotidiano.

Embrião selecionado - Técnica faz bebê nascer sem gene de anemia: segundo médico, é a primeira vez que a sequência gênica da doença é feita para fins reprodutivos. Folha de S.Paulo, São Paulo, 9 mai. 2005b. Folha Cotidiano, p. C 4.

Preço de remédio varia conforme o médico. Folha de S.Paulo, São Paulo, 12 mai. 2005c. Folha Cotidiano, p. C 1.

(Reportagem local). Dobra número de estrangeiras que vêm ao Brasil tentar engravidar. Folha de S.Paulo, São Paulo, 12 jun. 2005d. Folha Cotidiano, p. C 5.

. (Enviada especial a Copenhague). Gravidez múltipla já é considerada um risco à saúde. Folha de S.Paulo, São Paulo, 27 jun. 2005e. Folha Cotidiano, p. C 4.

COLLUCCI, Cláudia e BASSETTE, Fernanda. Sem aval médico, droga para ter filhos traz riscos. Folha de S.Paulo, São Paulo, 13 mai. 2005. Folha Cotidiano, p. C 8. 
CONNOR, Steve. Mutantes de verdade. Folha de S.Paulo, São Paulo, 20 mar. 2005. Caderno mais! Mais ciência, p. 9.

COSTA, Humberto. Quem tem medo das células-tronco? Folha de S.Paulo, São Paulo, 27 jun. 2005. Opinião: Tendências/debates.

ESHACH, Haim. Bridging in-school and out-ofschool learning: formal, non-formal, and informal education. Journal of Science Education and Technology, Nova York, v. 16, n. 2, abr. 2007.

FOLHA DE S.PAULO. Aos 66, mulher dá a luz um bebê: a romena Adriana Iliescu se torna a mãe mais velha a ter uma criança. Folha de S.Paulo, São Paulo, 17 jan. 2005a. Folha Mundo, p. A 7.

Célula-tronco adulta age como embrionária: descoberta facilita cultivo. Folha de S.Paulo, São Paulo, 9 mai. 2005b. Caderno Mais! Ciência em Dia.

Esterilidade preocupa mulher jovem. Folha de S.Paulo, São Paulo, 05 jun. 2005c. Folha Cotidiano, p. C 1.

Ministério da Saúde volta a defender estudo. Folha de S.Paulo, São Paulo, 15 jun. 2005d. Folha Ciência, p. A 18.

FREIRE, Paulo. Pedagogia da autonomia: saberes necessários à prática educativa. 29. ed. São Paulo: Paz e Terra, 1996.

GOHN, Maria da Glória. Educação não-formal, participação da sociedade civil e estruturas colegiadas nas escolas. Revista Ensaio: Avaliação e Políticas Públicas em Educação, Rio de Janeiro, v. 14, n. 50, p. 27-38, jan./ mar. 2006.

KÖRBES, Clecí. Educação não-formal e informal em ciência e tecnologia: divulgação científica e formação de opinião sobre reprodução assistida e seus desdobramentos na Folha de S.Paulo. Dissertação (Mestrado em Educação) - Programa de Pós-Graduação em Educação, UFPR, Curitiba, 2008.

KÖRBES, Clecí; INVERNIZZI, Noela. Divulgação científica e educação não-formal na im- prensa: o caso da reprodução assistida. In: SEMINÁRIO NACIONAL DE EDUCAÇÃO PROFISSIONAL E TECNOLÓGICA, 1, 2008, Belo Horizonte. Anais... Belo Horizonte: Cefet/MG, 2008a, p. 1-13. 1 CD-ROM.

Reprodução assistida e gênero através da imprensa. In: SEMINÁRIO INTERNACIONAL FAZENDO GÊNERO: CORPO, VIOLÊNCIA E PODER, 8, 2008, Florianópolis. Anais... Florianópolis: Editora Mulheres, 2008b, p. 1-7. 1 CD-ROM.

LEITE, Marcelo. Conservadorismo e célulastronco. Folha de S.Paulo, São Paulo, 09 jan. 2005a. Caderno Mais! Ciência em Dia, p. 9.

A ressaca das células-tronco. Folha de S.Paulo, São Paulo, 26 jun. 2005b. Caderno Mais! Ciência em Dia, p. 9.

Embriões desarmados. Folha de S.Paulo, São Paulo, 24 out. 2005c. Ciência em Dia.

CNPq conclui edital para célulastronco: pesquisa ainda poderá ser barrada pelo Supremo, que vai examinar ação direta de inconstitucionalidade. Folha de S.Paulo, São Paulo, 21 nov. 2005d. Folha Ciência, p. A 14.

LEWENSTEIN, Bruce V. Models of Public Communication of Science \& Technology. Public Understanding of Science. Ithaca, NY: Cornell University, 2003. Disponível em: $<$ www.dgdc.unam.mx/Assets/pdfs/sem feb04.pdf>. Acesso em: 23 jul. 2010.

LIBÂNEO, José Carlos. Didática. São Paulo: Cortez, 1994. (Coleção Magistério $2^{\circ}$ grau. Série formação do professor).

LOPES, Adriana Dias. Gravidez a soldo: a barriga de aluguel tornou-se um negócio bem rentável no Brasil, apesar de proibido. Revista Veja, ed. 2.059, 07 mai. 2008. Disponível em: <http://veja.abril.com.br/070508/ p_140.shtml>. Acesso em: 25 maio 2008.

LOPES, Reinaldo José. Verba não atinge pesquisas com embrião. Folha de S.Paulo, São Paulo, 31 ago. 2005a. Folha Ciência, p. A 22. 
Equipe deriva células sem matar embrião: dois estudos publicados ontem ajudam a contornar dilemas éticos na obtenção de células-tronco embrionárias. Folha de S.Paulo, São Paulo, 17 out. 2005b. Folha Ciência, p. A 18.

LOZANO, Mónica. Programas y experiencias en popularización de la ciencia y la tecnología. Panorámica desde los países del Convenio Andrés Bello. Bogotá: Convenio Andrés Bello, 2005. (Serie Ciencia y Tecnología).

LUNA, Naara. Provetas e clones: uma antropologia das novas tecnologias reprodutivas. Rio de Janeiro: Ed. Fiocruz, 2007.

MARANDINO, Martha et al.. A educação nãoformal e a divulgação científica: o que pensa quem faz? In: ENCONTRO NACIONAL DE PESQUISA EM ENSINO DE CIÊNCIAS ENPEC, 4, 2004, Bauru. Atas... Bauru, 2004. Disponível em: <http://paje.fe.usp.br/estrutura/ geenf/textos/oquepensa_trabcongresso5.pdf $>$. Acesso em: 30 maio 2008.

MILLER, Steve. Public understanding of science at the crossroads. Public Understanding of Science, v. 10, n. 1, p. 115-120, 2001. Disponível em: <http://pus.sagepub.com/ cgi/content/abstract/10/1/115>. Acesso em: 20 abr. 2009.

NOGUEIRA, Salvador e LOPES, Reinaldo José. Grupos estão prontos para estudar embrião. Folha de S.Paulo, São Paulo, 06 mar. 2005. Folha Ciência, p. A 33.

NOGUEIRA, Salvador. Estudo expõe outro lado de célula-tronco. Folha de S.Paulo, São Paulo, 13 abr. 2005. Folha Ciência, p. A 16.

PROGRESS. Geneva, Switzerland: World Health Organization, n. 63, 2003. Disponível em: <www.who.int/reproductivehealth/ publications/infertility/progress63.pdf $>$. Acesso em: 12 ago. 2009.

REUTERS. Morre a mãe mais velha do mundo. TV iG: vídeo publicado em 16 jul. 2009. Disponível em: <http://tvig.ig.com.br/136160/ morre-a-mae-mais-velha-do-mundo.htm >. Acesso em: 18 ago. 2009.

RIBEIRO, Cláudia Regina e ROHDEN, Fabíola. A ciência na mídia e as estratégias de reafirmação da bipolaridade entre os gêneros: o caso do Globo Repórter. Cadernos Pagu, n. 32, p. 267-299, 2009. Disponível em: <www.scielo.br/pdf/cpa/n32/n32a09.pdf> Acesso em: 03 ago. 2010.

RODRIGUES, Diego; NUNO, Fernando; RAGGIOTTI, Naiara. Larousse ilustrado da lingua portuguesa. São Paulo: Larousse do Brasil, 2004. 977 p.

ROHDEN, Fabíola. A construção da diferença sexual na medicina. Cadernos de Saúde Pública, Rio de Janeiro, v. 19, supl. 2, p. S201-S212, 2003. Disponível em: <www.scielo. $\mathrm{br} / \mathrm{pdf} / \mathrm{csp} / \mathrm{v} 19 \mathrm{~s} 2 / \mathrm{a02v19s2.pdf}>$. Acesso em: 21 set./2010.

O império dos hormônios e a construção da diferença entre os sexos. História, Ciências, Saúde - Manguinhos, Rio de Janeiro, v. 15, supl., p. 133-152, jun./2008. Disponível em: <www.scielo.br/scielo.php?pid= S0104-59702008000500007\&script $=$ sci_ arttext>. Acesso em: 21 set./2010.

RUTSTEIN, Shea O. e SHAH, Iqbal H. Infecundity, Infertility, and Childlessness in Developing Countries. DHS Comparative Reports n. 9. Geneva: World Health Organization/Calverton, MD: Measure DHS PLus, 2004. Disponível em: <www.measuredhs. com/pubs/pdf/CR9/CR9.pdf $>$. Acesso em: 25 maio 2008.

SAVIANI, Dermeval. Pedagogia histórico-crítica: primeiras aproximações. 8. ed. revista e ampliada. Campinas, SP: Autores Associados, 2003 (Coleção Educação Contemporânea).

TAMANINI, Marlene. Quando as tecnologias colocam problemas que elas não resolvem. Florianópolis: UFSC, 2006. Disponível em: $<$ www.fazendogenero7.ufsc.br/artigos/M/ Marlene_Tamanini_48.pdf $>$. Acesso em: 26 mar. 2008. 
ZANINI, Fábio e CONSTANTINO, Luciana.

Câmara decide sobre células de embrião.

Folha de S.Paulo, São Paulo, 2 mar. 2005.

Folha Ciência, p. A 14.

Recebido em 25/01/2010

Aprovado em 15/09/2010 